https://doi.org/10.19195/2084-2546.29.7

\title{
DANIELA FUMIS
}

ORCID: 0000-0002-6082-8737

Universidad Nacional del Litoral

Correo: danielafumis@gmail.com

\section{"Yo no vi entonces sino su mucho deseo". Memorias plurales en Luis Antonio de Villena}

Palabras clave: memoria - primera persona - Villena - pasado - deseo.

\section{Resumen}

La propuesta estética de Luis Antonio de Villena se distingue por la exploración en primera persona del devenir deseante de la escritura. En este sentido, Lúcidos bordes del abismo. Memoria personal de los Panero (2014) constituye una experiencia de singular potencia en la indagación del relato del pasado en términos de lo íntimo. El presente trabajo sostiene como hipótesis que la problematización de las figuraciones públicas de la familia Panero propuesta por el texto, a partir del énfasis en una dimensión vincular, permite a la voz dar cuenta de sí de manera desplazada, reconvirtiendo la fuerza de la primera persona en dimensión colectiva. La memoria se postula, entonces, como asunto público y se transforma en dispositivo de reflexión — no circunscripto en términos genéricos- . De esta manera, imaginar el pasado en común desde el derribo de las percepciones mitificadas será un modo de transformar recuerdo en proyecto inacabado.

\section{Introducción}

¿Cómo se cuenta la historia de una vida? ¿Es posible construir el relato de uno mismo sin traicionarse? Y a la vez ¿hay manera de escapar de la tiranía de la primera persona cuando de lo que se trata es de dar cuenta de sí? Estas preguntas se vuelven especialmente significativas a la hora de abordar la obra del escritor Luis Antonio de Villena, en la que la condición autorreferencial se vuelve rasgo constitutivo. La trayectoria intelectual de este autor se singulariza en el campo literario español por su vigencia sostenida en el tiempo gracias a una producción prolífica y marcada por una amplitud de intereses. La noción de trayectoria como "serie de posiciones sucesivamente ocupadas por un mismo agente [...] en un espacio en sí mismo en movimiento y sometido a incesantes transformacio- 
nes" (Bourdieu, 1997: 82) adquiere particular relevancia para el caso, dado que la figura de Villena permite rastrear los desplazamientos discursivos ocurridos en torno a las disidencias sexuales en la historia contemporánea de España.

En este sentido, Alberto Mira (2007: 27) distingue tres modelos conceptuales en el tratamiento literario de la homosexualidad en España a lo largo del siglo XX: el modelo malditista, el homófilo y el camp o la pluma. El autor señala que los dos primeros irán perdiendo potencia en el tránsito de una experiencia forzosamente armarizada a una identidad gay potencialmente pública que se expresa en primera persona (Mira, 2007: 416). Siguiendo esta línea, Mira asegura que España careció por mucho tiempo de una tradición de figuras de referencia en la cultura homosexual propiamente hispánica (128) y, en el caso de Villena, su imagen adoptará inicialmente las características del dandismo (cercano al malditismo) como un modo de gestionar la homosexualidad en dimensión pública.

La figura de Villena resulta particularmente atractiva a este respecto, en la medida que su obra ha explorado la potencia de la primera persona ligada al nombre de autor de manera temprana, tanto en lírica como en narrativa y en ensayos. $\mathrm{Su}$ incursión en el género memorialístico se consuma de manera explícita en la trilogía constituida por El fin de los palacios de invierno (2015), Dorados días de sol y noche (2017) y Las caídas de Alejandría (2019). No obstante, ficciones como Madrid ha muerto (1999), El bello tenebroso (2004) o Patria y sexo (2004) merodean de igual manera cierta condición ambigua en torno a la vivencia propia. En esta misma dirección, es posible rastrear en sus ensayos críticos la conformación de una historia personal en la que, a la vez que recorre una obra particular, el yo se figura en su experiencia lectora. De hecho, el trabajo crítico villeniano de exhumación y rehabilitación de las figuras de autores cuyas biografías homosexuales han quedado ocluidas por la censura del canon (Antonio de Hoyos, Álvaro Retana, Luis Cernuda, Jaime Gil de Biedma, entre otros), constituye una particular operación de intervención que distingue en términos de posición la trayectoria de nuestro autor. Sin embargo, en esta tendencia general, se recorta un gesto de productividad singular en el texto Lúcidos bordes del abismo. Memoria personal de los Panero (2014). Allí, Villena recuerda y trae hacia una zona queer la historia ampliamente conocida de la familia Panero. Sin embargo, a pesar de la promesa de su título, no se trata solo de construir la "memoria personal" de los miembros de una familia, sino que, a partir de una sucesión de anécdotas y de ejercicios críticos sobre la producción literaria de estos escritores, el relato logra formular una pregunta por la memoria como lugar de disidencia. Villena escudriña, así, una memoria sentimental compartida (Ros Ferrer, 2020) a los fines de desnaturalizar lo generacional y sus consensos sobre el pasado, desde la apuesta presente sobre el terreno de la intimidad como campo de posibles.

Por tanto, nuestro trabajo sostiene como hipótesis que en Lúcidos bordes del abismo la problematización de las figuraciones públicas cristalizadas en clave afectiva permite a la voz dar cuenta de sí de manera desplazada y, simultáneamente, reconvertir la potencia de la primera persona en dimensión colectiva. A efectos de examinar dicha hipótesis, nuestro recorrido indagará en el modo 
en que esta operación de desvío en la memoria (de lo personal a lo colectivo) se produce en el relato sobre un doble movimiento: un distanciamiento inicial en la vivencia (en la figura del fugitivo) y una aproximación posterior desde la escritura en clave de presente.

\section{La intimidad singular: la autocreación como disenso}

Lúcidos bordes del abismo. Memoria personal de los Panero se inscribe al interior de la obra de Luis Antonio de Villena como una propuesta coherente con un programa narrativo que se aproxima con insistencia a la vivencia personal. Sobre este universo localizado y específico, la configuración de una voz sobre los matices de la primera persona posibilita abrir la discusión en torno al estatuto de sus textos en la estela de los géneros de la autorreferencia. De acuerdo con Giordano (2019: 183), en la pregunta por cómo se cuenta una vida se encuentran implícitas dos dimensiones: una, que involucra los modos del relato de una historia subjetiva, sostenida en su condición de artificio por estrategias retóricas en el marco de ciertos imaginarios culturales; otra, atenta a lo incierto en el acto mismo de relatar (aquello que se cuenta de por sí, ahí donde el control se escapa). No obstante, al examinar específicamente la producción de Villena resulta ineludible enfatizar en esos lugares en los que una vida cuenta al asumir "un sentido estético y moral determinado" (Giordano, 2019: 183). En efecto, sobre el carácter transversal del devenir deseante de la escritura en términos de tránsito del cuerpo a la palabra, habría que considerar "[1]a figuración del yo íntimo como un punto de intersección, donde una biografía cualquiera se vuelve asunto público por el sentido político de comunidad que encarna y por los valores éticos que representa" (Scarano, 2011: 17). De este modo, el problema en esta obra excede la discusión sobre el anclaje fáctico de lo narrado, y por fuera de las derivas en torno a un pacto autobiográfico (Philippe Lejeune) frente a un pacto autofictivo (Manuel Alberca) ${ }^{1}$, podría identificarse una forma no híbrida sino diversa ${ }^{2}$, que se resiste a ser clasificada y que funciona asentada sobre la intimidad en lo que esta tiene de verdad para quien habla en términos de una ética.

Lo íntimo, en el sentido de Scarano (2011), podría ser entendido en la escritura de Villena como las formas en las que se interviene sobre una sensibilidad social. Por tanto, las modulaciones de la voz en primera persona importan no en cuanto a su condición referencial ${ }^{3}$, sino en la dimensión del gesto. Dicho

${ }^{1}$ Sobre la autoficción en relación con la infancia en Villena han indagado Prósperi (2009) y Ramírez (2019); con relación a las autopoéticas, Prósperi (2012).

2 Se alude como "forma diversa" a un modo del relato que no se deja aprehender en términos genéricos y que dialoga con otras textualidades permeables al desorden y a la inestabilidad del recuerdo.

${ }^{3}$ El mismo texto lo plantea en estos términos: "Este es un libro sobre mi relación personal con los miembros de la familia Panero, más con unos que con otros. Otras personas tendrán otras visiones o ángulos de mira, igualmente respetables" (Villena, 2014: 205). 
gesto involucra la revisitación de escenas altamente transitadas en una memoria sentimental compartida, para proponer una fisura por la que se filtra no solo la singularidad de una voz sino una desestabilización del relato del pasado, que interroga el tiempo presente.

Anna Caballé (2001: 40) sostiene que "[e]1 franquismo trajo consigo una especie de impotencia autobiográfica". Vale decir, que la toma de la palabra en cuanto "compromiso estético con la individualidad" quedó obturada en dicho período bajo una suerte de lectura épica o simbólica de lo que el sujeto representaba como exponente de un todo social (Caballé, 2001: 40). En una proyección posible, la contundencia del gesto de ruptura villeniano podría entenderse en relación con lo que Loureiro (2001: 148), leyendo con Levinas, reflexiona a propósito de la autobiografía: "[...] no es una restauración del pasado sino un acto singular de autocreación como respuesta, responsabilidad y promesa (de verdad). Como tal, este acto es siempre dialógico, está dirigido al otro, y por lo tanto es siempre intrínsecamente contestable e incompleto". Estas reflexiones en torno al trabajo de la primera persona importan dado que la tendencia a la autorreferencialidad puede reconocerse como una opción temprana en la obra de Villena. Su poesía primera va a la búsqueda de sus mitos al punto que el yo lírico mismo se transforma en mito literario (Quintana Tello, 2009: 41). No obstante, a partir de Hymnica, un poemario que coincide con "una etapa de liberación personal (que casi coincidió con la del país)" (Bonilla, 2005, citado por Prósperi, 2012: 186) resulta posible distinguir un anclaje sostenido en el nombre propio textualizado 4 . El conocido poema "La vida escandalosa de Luis Antonio de Villena" delinea los perfiles de este sujeto lírico tramado minuciosamente a lo largo de toda su obra:

\begin{abstract}
Paganismo, culto a la belleza efébica, la rareza y la elegancia, el malditismo, el clasicismo como apetencia, la vanguardia como actitud, la extravagancia como método, la brillantez y el éxito social contrastados convenientemente con el desgarro y la entrega a los placeres prohibidos, todo eso sabiamente combinado por el poeta Villena ha ido configurando la personalidad del Villena personaje, que desde luego tiene mucho que ver con el poeta [...] (Infante, 1990, citado por Quintana Tello, 2009: 162).
\end{abstract}

Sin embargo, las textualidades de Villena han dejado expuesto que el personaje se construye en lo que de vivencia tiene la literatura. En este sentido, los volúmenes dedicados a sus obras de referencia (las de Retana, Kavafis, Cernuda, Gide, entre otras), ponen de manifiesto lo que el ejercicio crítico revela de sí en lo que se lee. El trabajo de Villena se podría analizar a la luz de la reflexión de Pauls (2018: 113) sobre Barthes: “[...] cuando lee [...] literatura vieja, indigna incluso de figurar en el panteón de viejos reivindicado por los modernos, Barthes ejerce el verdadero poder de leer: el poder de resucitar. La lectura es transfusión de sangre, shock eléctrico, posesión". Desde la primera línea del relato "Han muerto ya todos" (Villena, 2014: 7) comprendemos que la estrategia villeniana

${ }^{4}$ Para Quintana Tello (2009: 163), los procedimientos del espejo y la máscara permanecen en sucesivos poemarios, aunque la imagen de sí vaya mutando en el tiempo. 
funciona en esta misma dirección: disponer un yo-lector-crítico que, al "resucitar" una vivencia tramada a fuerza de literatura, se lee (a sí mismo).

En ese comienzo, en el que el énfasis se sitúa en la muerte de los sujetos de los que se hablará, la ilusión de la posibilidad de aprehender una biografía ajena como totalidad cerrada está latente. Sin embargo, el relato dejará expuesto un entramado en el que el yo que lee tensa pasado y presente en el recuerdo, para delinear sus figuras como superficies abiertas.

\section{La intimidad en plural: la ruptura de los mitos como abismo de presente}

Lúcidos bordes del abismo. Memoria personal de los Panero relata el devenir de las relaciones entre Villena y los Panero a lo largo del tiempo ${ }^{5}$. La apuesta del texto consiste en construir una biografía para cada uno, pero exponiendo, a la vez, los problemas de la distinción entre vida y literatura cuando la existencia adquiere una condición bioliteraria (Labrador Méndez, 2017), vale decir, cuando la literatura se convierte en la condición de posibilidad y de resistencia para un ser en el mundo.

A lo largo del relato se encadena una serie de episodios que no siguen estrictamente una lógica progresiva y en los que la trama de la vivencia y la literatura se gestiona como construcción de un espacio amoroso en la crítica. Así, las figuras pueden cifrarse en poemas que Villena interpreta como autorreferenciales ${ }^{6}$ y discutirse, a continuación, asumiéndolos como ficción fundacional: los poemas no son en los Panero un producto o resultado sino la alquimia que infunde el hálito primitivo a cada uno de ellos.

Por otra parte, la performance de la revelación en Villena no queda del lado de la infidencia (o el chisme) porque de lo que se trata es de craquelar la dimensión mítica que cristaliza y transforma en homogéneo lo diverso. Podemos leer esto en sintonía con Martínez Expósito (2004: 47):

La escritura queer no se contenta con hablar de la experiencia gay o lesbiana, o con airear la existencia de sexualidades no heterosexuales, sino que lucha por denunciar y subvertir las ideas dominantes (heterosexistas) sobre la sexualidad [...].

La idea de lo dominante cobra sentido en relación con lo mítico a partir del alto grado de conocimiento que existe en la escena pública sobre las circunstancias familiares de los Panero. En este sentido, la historia es conocida: el apellido Panero se convierte en sinécdoque de la Transición cuando en 1976 se estrena

${ }^{5}$ Concretamente, desde el encuentro en 1968 con la poesía de Leopoldo Panero hasta el presente de la escritura en el año 2014.

6 "Un étranger" para Juan Luis Panero, "Territorio del cielo" para Leopoldo María Panero (un poema dedicado a su madre) y "Un arte de vida" para sí mismo. 
la película de Jaime Chávarri El desencanto. Si la muerte de Francisco Franco se gestionó en el imaginario público como la muerte del padre (Vilarós, 1998), a la brevedad el término desencanto daría carta de naturaleza a una actitud que identificaba una cierta mirada hacia la Transición en el posfranquismo en clave de familia (Fumis, 2018). En este sentido, dado que el franquismo obstruyó la primera persona o la habilitó solo a condición de presentarse como totalidad resuelta, la toma de la palabra en primera persona que propone la película supone un desvío frente al mandato de armarización de la intimidad (Chamouleau, 2017).

Ahora bien, si Mira (2007: 416) sostiene que la dimensión pública de una identidad gay en primera persona se expone durante la Transición como metonimia de una transición en términos "de estructuras y mentalidades", Chamouleau complejizará el abordaje del proceso al problematizar la distinción naturalizada de lo público y lo privado y el discurso de lo privado como "conquista democrática". Para Chamouleau (2017: 345-346), el concepto de privacidad operativiza (al menos) dos efectos: por un lado, logra "[...] desarticular las subjetividades que concibieron lo íntimo como lugar donde crear vínculos sociales y comunitarios y politizar un desacuerdo radical [...]"y, por otro, actúa como una "tecnología de la transparencia y el pudor" (331) que continúa legitimando la moral católica como modelo del buen comportamiento para el funcionamiento social. La privacidad requerirá performarse (a través del secreto y el recato) en función de la ocultación de lo íntimo disensual (348). Este abordaje en torno a la instrumentalización de lo privado como un modo de cercar las disidencias permite vislumbrar, en principio, la resistencia radical de las trayectorias involucradas en la trama de Lúcidos bordes del abismo. A mediados de los setenta, tanto los Panero como Villena discuten de modo explícito esta demanda de inscripción y de "guardado", reclamando su existencia desde la drástica exposición en sintonía ambigua.

En esta dirección, y en un sentido amplio, el relato adquiere el matiz del testimonio. Pero pregunta Eribon (2019: 19): “¿quién habla cuando uno habla de sí mismo? ¿Y de quién habla? [...] Toda empresa de autoanálisis contiene y pone en juego una teoría social y política del sujeto y los procesos de subjetivación". Sin embargo, si la primera persona trabaja sobre la "memoria personal" de otras trayectorias públicas, la pregunta debería reformularse en términos de "¿qué habla cuando Villena dice yo?".

Villena se pregunta (2014: 184) “¿[q]ué era el mito de los Panero? ¿No había mito o en realidad y hablando más propiamente no era «mito» sino mitos diversos?". A la luz de la revisión que la Transición como relato ha sufrido en las últimas décadas, la pregunta inevitable debería indagar sobre el trasfondo del retorno. Si el espacio de enunciación sobre cuya hegemonía se dirime el debate público organiza la memoria ligada a un repertorio generacional de códigos emocionales (Ros Ferrer, 2020: 70), el gesto de Villena de derribar los mitos del pasado a la luz del presente adquiere toda su dimensión. En la medida en que las prácticas emancipatorias se encuentran ligadas a los modos de entender las formas de 
resistir a lo largo de la historia y las estrategias de discusión de los mecanismos de dominación varían en función de distintos ritmos (Eribon, 2019: 13), el relato de Villena se revela como un ejercicio de la memoria en primera persona que busca situar el recuerdo a destiempo para rehabilitar la potencia de la vivencia pasada en sintonía con un modo otro de entender la democracia en la actualidad (Labrador Méndez, 2017). De esta manera, será significativo constatar el modo en que la indagación de la biografía como "una geografía de afectos" (Preciado, 2019: 53) en el vaivén entre la historia de los otros y la historia personal, permite una historización de los vínculos que se convierte en una puesta de manifiesto de su contundencia en términos de toma de la palabra.

Una pregunta clave: "Pensé: ¿Se acordará de nuestras antiguas noches cazando chicos? Repito que nunca lo supe" (Villena, 2014: 164). En el relato que se trama desde el recuerdo, se instala como operación un movimiento progresivo de distanciamiento que regresa a la vivencia desde la confesión de la huida: así el retorno íntimo de Villena busca desarticular el mito de los Panero desde su propia condición de fugitivo. "Claramente huir y que no te viera, porque te seguía, y no llegabas a entenderlo" (Villena, 2014: 87) y también "Pero ya te he invitado y nunca has venido... Tenía toda la razón. Y tampoco fui" (145). La operación de desvío, entonces, señala un repliegue sobre la memoria como territorio y señala, como primer movimiento, un distanciamiento inicial en la vivencia: aunque atravesado por el vínculo, Villena elige huir de los Panero. Por tanto, en su relato, se figura como un fugitivo que escapa, fundamentalmente, de la tentación de la autodestrucción.

Sostiene Villena (2014: 204) al respecto de los Panero:

No creyeron en las biografías como vanas estatuas de mármol. Pusieron temblor y emoción y no evitaron ni la furia, ni las lágrimas. Ni la pasión, pues, ni claro está los errores. [...] Su historia global bien podría definirse como una consumada teoría de la destrucción.

Las formas de la destrucción serán leídas en su texto como irrupciones vitales en las que el deseo dinamiza la cotidianidad a partir del trabajo de la fantasía. La primera forma de destrucción (la familiar) es la que se toma como punto de partida: el relato comienza con algunos sucesos que tuvieron lugar durante el estreno de El desencanto y sigue una línea que se cierra con la muerte del último del linaje: Leopoldo María. En esta dirección, Villena hace trabajar el recuerdo exponiendo lo que ha demostrado como su propia experticia crítica: la mostración del artificio de las figuras en la trama que construyen las palabras y los gestos. El caso de los dos hermanos mayores es el de mayor significatividad porque, en el devenir del relato, los lugares asignados imaginariamente a cada uno irán agrietándose con un enfático quiasmo: la desconexión progresiva de Leopoldo María y su "desaparición" psíquica no evitarán la conversación del yo con el que habita en sus poemas; la tesitura de Juan Luis elevará su eventual entrega apasionada a la vivencia. 
Todas las situaciones de ligue compartidas podrían resumirse como: "Yo no vi entonces sino su mucho deseo (también yo deseaba)" (Villena, 2014: 24). Sin embargo, dos episodios en concreto pueden identificarse especialmente como los que expresan la contundencia del deseo y se imponen como el resquebrajamiento de las figuras a partir del secreto. El primero de ellos alude a un encuentro compartido entre Leopoldo María y Villena con dos estudiantes de Valladolid en la casa madrileña de los Panero. En este episodio puntual, la fascinación de los cuerpos ilumina el modo en que se trama, en la casa familiar, el éxtasis del sexo a partir de una intervención materna en su advertencia: "que no quede encendido el gas" (67). La trama de los afectos se vuelve diversa y remite a los modos en que se conjuga el exceso y la domesticidad bajo lo que la ironía simboliza: que todo puede estallar cuando el placer enajena.

Por su parte, el episodio que involucra a Juan Luis refiere a un encuentro sensual con Juan Gil-Albert. Juan Luis se desnuda y se ofrece al maestro como una celebración de la experiencia compartida. En ambos casos el cuerpo, como dispositivo textual, ingresa al relato como parte de un régimen de memoria (Ros Ferrer, 2020) a través de ciertas representaciones ligadas, a su vez, a un cuerpo de valores, en este caso, especialmente estéticos. Los cuerpos son bellos y excesivos como bella y excesiva es la escritura que los busca.

Así, si con el avance del relato la voz narradora termina figurándose como fugitivo, Villena huye de los Panero en la historia para retornar en el relato transformado en primera persona junto a los otros. Y en ese punto resulta factible detectar el segundo movimiento en la operación de desvío: se trata de la aproximación posterior en la escritura en clave de presente.

En el texto no se huye de los muertos; por el contrario, se va a su encuentro. Al delinear una geografía de afectos situada, la sociabilidad se muestra como estrategia de intervención sobre los ritmos del espacio público durante un período determinado (Smith, 2007) con especial énfasis en aquellos lugares que ya no existen. Pero esta sociabilidad sugiere, asimismo, la forma en que se aprendieron a gestionar colectivamente los dispositivos represivos somatizados en estos cuerpos (Labrador Méndez, 2017): a fuerza de escritura (de poesía) como liberación. Por este motivo, lo afectivo dinamiza lo aparentemente acabado para transformarlo en una postulación sobre lo que significa reconocer-se en el relato del pasado: ir al encuentro de zonas difusas, incomprensibles, asumir lo incómodo, lo que no se deja decir con facilidad, desplazar la escritura hacia el abismo.

Es en este lugar donde la memoria se reivindica como asunto público y el texto se transforma en dispositivo de reflexión - no circunscripto en términos genéricos - sobre las estrategias desde las que, asumiéndose como subjetividades deseantes, las voces pueden intervenir en los condicionamientos sociales que las restringen. Se trata, en definitiva, de "[...] imaginar teatros disidentes en los que sea posible producir otra fuerza performativa. Inventar una nueva escena de la enunciación [...]" (Preciado, 2019: 124). Y, así, la escritura de la vida en común (aun en las diferencias) se convierte en una práctica performática que logra, en un contra-movimiento, transformar la huida en retorno productivo a la escritura como horizonte de lo todavía por-venir. 


\section{Conclusiones}

Hacia el final sostiene el autor: "[E]n este análisis de lo vivido, yo mismo me he sorprendido con algunos cambios en mi estima" (Villena, 2014: 205). Volver sorprendido, hallar la fisura, situarse en una zona liminar en la que lo que retorna es la constatación del pasado como proyecto siempre inacabado. De esta manera, el carácter incompleto e incierto del relato de sí asume otro cariz en Villena cuando se expone en su sentido público y colectivo.

Nuestro recorrido tomó como punto de partida el rasgo autorreferencial de la poética villeniana a fin de indagar sobre sus matices particulares en una obra en la que el eje se sitúa en el encuentro-con-otros desde una apuesta por la memoria.

De comienzo, fue posible reconocer en la tendencia villeniana a la inscripción del nombre propio una opción temprana de desacralización de mitos. Sin embargo, Lúcidos bordes del abismo afronta el dilema de desplazar el mito personal hacia los mitos en la escena colectiva. Nuestra lectura indagó a este respecto en las tensiones entre lo privado y lo público para, finalmente, desvelar la potencia de una memoria a destiempo que recupera la anécdota privada para preguntarse por las formas en las que el pasado interviene en la construcción del presente. En este sentido, el análisis del texto de Villena permitió reconocer el retorno del yo desde el recuerdo de la vivencia deseante como territorio incompleto y como abismo que deviene en escritura (la del texto que leemos). Se dejó expuesto, en esa dirección, que la palabra trabaja sobre una operación de doble movimiento: de ruptura, en función de un distanciamiento fugitivo, y de aproximación en términos de escritura, como un modo de desbaratar lo mítico y de asumir lo por-venir. Así, el pasado como proyecto inacabado demarca el presente como un espacio que se habita siempre con otros y en otros. Memoria personal a destiempo como memorias siempre en plural.

\section{Referencias bibliográficas}

Bourdieu, Pierre (1997): "La ilusión biográfica", Razones prácticas. Sobre la teoría de la acción, Barcelona, Anagrama, pp. 74-83.

Caballé, Anna (2001): "Escribir el pasado, yendo al futuro", Anales de literatura española, 14, pp. 29-40, <http://www.cervantesvirtual.com/obra/escribir-el-pasado-yendo-al-futuro/>.

Chamouleau, Brice (2017): Tiran al maricón. Los fantasmas queer de la democracia (1970-1988), Madrid, Akal.

Eribon, Didier (2019): Principios de un pensamiento crítico, Buenos Aires, El cuenco de plata.

Fumis, Daniela (2018): "Ficciones familiares en Transición", Actas I Jornadas de Jóvenes Hispanistas, Buenos Aires, UBA, <http://eventosacademicos.filo.uba.ar/index.php/JJH/IJJH>.

Giordano, Alberto (2019): “¿Cómo se cuenta una vida? Apuntes de lectura”, Atenea, 520, pp. 183-193, $<$ https://revistas.udec.cl/index.php/atenea/article/view/1605>.

Labrador Méndez, Germán (2017): Culpables por la literatura. Imaginación política y contracultura en la transición española (1968-1986), Barcelona, Akal.

Loureiro, Ángel (2001): “Autobiografía: El rehén singular y la oreja invisible”, Anales de literatura española, 14, pp. 135-150, <http://www.cervantesvirtual.com/obra/autobiografia-el-rehensingular-y-la-oreja-invisible/>. 
Martínez Expósito, Alfredo (2004): Escrituras torcidas. Ensayos de crítica “queer”, Barcelona, Laertes.

Mira, Alberto (2007): De Sodoma a Chueca. Una historia cultural de la homosexualidad en España en el siglo $X X$, Barcelona, Madrid, Egales.

Pauls, Alan (2018): Trance, Buenos Aires, Ampersand.

Preciado, Paul B. (2019): Un apartamento en Urano, Barcelona, Anagrama.

Prósperi, Germán Guillermo (2009): "Niñez, autoficción y memoria en Luis Antonio de Villena", Siglo XXI. Literatura y cultura españolas, 7, pp. 157-167, <https://revistas.uva.es/ index.php/ sigloxxi/article/view/1445>.

Prósperi, Germán Guillermo (2012): “«Las metáforas que brotan del deseo»: escenas autopoéticas en Luis Cernuda y Luis Antonio de Villena”, Texturas, 12, pp. 175-190, <https://doi.org/10.14409/ texturas.vli12.2918>.

Quintana Tello, Belén (2009): Las voces del espejo: texto e imagen en la obra lírica de Luis Antonio de Villena, Zaragoza: Prensas Universitarias de Zaragoza.

Ramírez, Cristian (2019): "Luis Antonio de Villena: la memoria como constelación, un ejercicio", Álabe, 20, <http://dx.doi.org/10.15645/Alabe2019.20.3>.

Ros Ferrer, Violeta (2020): La memoria de los otros. Relatos y resignificaciones de la Transición española en la novela actual, Madrid, Frankfurt am Main, Iberoamericana-Vervuert.

Scarano, Laura (2011): "Intimidades de papel: la escritura poética del yo íntimo", Telar, Revista del Instituto de Estudios Latinoamericanos, 9, pp. 15-31.

Smith, Paul Julian (2007): "Espacios urbanos en la transición española: el caso de Luis Antonio de Villena", en Matzat Wolfgang (ed.), Espacios y discursos en la novela española del realismo a la actualidad, Madrid, Frankfurt am Main, Iberoamericana-Vervuert, pp. 117-123.

Vilarós, Teresa (1998): El mono del desencanto. Una crítica cultural de la transición española (1973-1993), Madrid, Siglo XXI de España.

Villena, Luis Antonio de (2014): Lúcidos bordes del abismo. Memoria personal de los Panero, Sevilla, Fundación José Manuel de Lara.

\section{"Yo no vi entonces sino su mucho deseo". Plural Memories in Luis Antonio de Villena}

Keywords: memory — first person — Villena — past — desire.

\section{Abstract}

Luis Antonio de Villena's aesthetic proposal is distinguished by the first-person exploration of the desire: body becomes a textual device. In this sense, Lúcidos bordes del abismo. Memoria personal de los Panero (2014) constitutes an experience of singular power in the investigation of the story of the past in terms of the intimate. The hypothesis of the present work maintains that the problematization of the public figurations of the Panero family allows the voice to give an account of itself in a displaced way: the first person is reconverted into a collective dimension. Then, memory is postulated as a public issue and becomes a device for reflection-not circumscribed in generic terms. In this way, imagining the common past since the demolition of mythologized perceptions will be a way of transforming textual memory into an unfinished project.

Fecha de recepción: 1 de octubre de 2020

Fecha de aceptación: 2 de mayo de 2021 